\title{
Pengaruh Komunikasi Interpersonal dan Latar Belakang Pendidikan terhadap Profesionalisme Kepala PAUD
}

\section{(The Influence of Interpersonal Communication and Educational Background on the Headmaster's Professionalism of PAUD)}

\author{
Dian Tri Utami ${ }^{*}$, Raihana ${ }^{2}$, Ida Windi Wahyuni ${ }^{2}$ \\ ${ }^{123}$ Pendidikan Guru Pendidikan Anak Usia Dini, Universitas Islam Riau \\ 1diantriutami@fis.uir.ac.id, 2raihana@fis.uir.ac.id,3idawindi@fis.uir.ac.id \\ *)corresponding author
}

$\begin{array}{ccc}\text { First received: } & \text { Revised: } & \text { Final Accepted: } \\ 25 \text { September 2020 } & 30 \text { September 2020 } & \text { 06 October 2020 }\end{array}$

\begin{abstract}
The professionalism headmaster of PAUD strongly influences the quality of PAUD institution. The low competence professionalism headmaster of PAUD is the leading cause of the low quality of education, including the headmaster of PAUD with limited insights regarding early childhood education, lack of communication with colleagues has an impact on motivation and morale found in the field. This research is a quantitative study with multiple regression analysis. This study aims to determine the effect of interpersonal communication and educational background on the professionalism headmaster of PAUD in Indragiri Hulu Regency. Data obtained from the results of the questionnaire distribution of the three variables which were analyzed by multiple regression analysis. The results showed that there was no significant influence between interpersonal communication and educational background on the professionalism headmaster of PAUD in Indragiri Hulu Regency. This is supported by the calculation of the significance test, where the results obtained by the value of $\mathrm{F}_{\text {count }}=$ 0.09 , which is smaller than the value of $F_{\text {table}}=3.13$. From the results of the study it can be concluded that the professionalism headmaster of PAUD cannot be separated from the element of educational background because the higher the level and suitability of the department, the more professional workers will be. Likewise, being professionalism depends on controlling the environment through communication.
\end{abstract}

Keywords: interpersonal communication, educational background, headmaster's professionalism

\begin{abstract}
Abstrak
Mutu suatu lembaga PAUD sangat dipengaruhi oleh profesionalisme kepala PAUD. Rendahnya kompetensi kepala PAUD menjadi penyebab utama mutu pendidikan menjadi rendah, diantaranya kepala PAUD dengan wawasan yang masih sempit terkait kePAUDan, kurangnya komunikasi dengan rekan kerja berdampak pada motivasi dan semangat kerja ditemui dilapangan. Penelitian ini adalah penelitian kuantitatif dengan analisis regresi berganda. Penelitian ini bertujuan untuk mengetahui pengaruh komunikasi interpersonal dan latar belakang pendidikan terhadap profesionalisme kepala PAUD di Kabupaten Indragiri Hulu. Data didapatkan dari hasil sebaran angket ketiga variabel yang dilanjutkan dengan analisis regresi ganda. Diperoleh hasilLpenelitian bahwa tidak terdapat pengaruh yang signifikan antara komunikasi interpersonal dan latar belakang pendidikan terhadap profesionalisme kepala PAUD di Kabupaten Indragiri Hulu. Hal ini didukung perhitungan uji signifikansi, dimana
\end{abstract}


diperoleh hasil nilai Fhitung $=0,09$ yang mana lebih kecil dari nilai Ftabel $=3,13$. Dari hasil penelitian dapat disimpulkan bahwa profesionalisme kepala PAUD tidak lepas dari unsur latar belakang pendidikan dikarenakan semakin tinggi strata dan kesesuaian jurusan nantinya akan mencapai pekerja yang profesional. Begitu juga menjadi profesionalisme tergantung pengendalian lingkungan melalui komunikasi.

Kata Kunci: komunikasi interpersonal, latar belakang pendidikan, profesionalisme kepala sekolah

\section{PENDAHULUAN}

Pendidikan yang melahirkan generasi progresif membutuhkan perangkat yang canggih, tidak hanya dari sarana prasarana fisik akan tetapi sarana non fisik yakni sumber daya manusia. Pendidik dan tenaga kependidikan menjadi pihak yang sangat berpengaruh dalam pencapaian mutu pendidikan yang berkualitas, terkhusus kepala pendidikan anak usia dini (PAUD). Kepala PAUD merupakan seseorang pemimpin yang menggerakan pendidik, peserta didik, wali peserta didik dan stakeholders PAUD untuk melakukan berbagai aktivitas sehingga terwujud pelaksanaan PAUD yang optimal.

Kepala PAUD dapat menggerakkan tenaga sumber daya manusianya ketika mampu menjadi kepala PAUD yang profesional. (Kusnandar, 2007) mengatakan profesionalisme merupakan kondisi, arah, nilai, tujuan, dan kualitas suatu keahlian dan kewenangan yang berkaitan dengan mata pencaharian seseorang. Kemudian, (Sudarwan Danim, 2002) mengartikan dimana profesionalisme yaitu komitmen para anggota suatu profesi untuk meningkatkan kemampuan profesionalnya dan terusmenerus mengembangkan strategistrategi yang digunakannya dalam melakukan pekerjaan sesuai dengan profesinya itu. Dapat disimpulkan profesionalisme yakni suatu komitmen dari anggota salah satu profesi yang akan terus memperbaiki serta meningkatkan keahlian dan kemampuan guna mencapai kualitas profesionalismenya secara berkelanjutan.

Kepala PAUD yang profesional adalah kepala PAUD yang memilliki standar dan kriteria pendidik dan tenaga kependidikan seperti yang tercantum pada Peraturan Menteri Pendidikan Dan Kebudayaan Nomor 137 Tahun 2014 tentang Standar Nasional Pendidikan, diantaranya memiliki komponen kompetensi yang meliputi kompetensi pedagogik, kompetensi profesional, kompetensi sosial dan kompetensi kepribadian. Artinya profesionalisme kepala PAUD ditunjukkan oleh standar kompetensi yang dimiliki oleh kepala PAUD itu sendiri.

Masing-masing kepala PAUD memiliki suatu cara dan strategi dalam memimpin. (Wiyani, 2015) bependapat bahwa idealnya kepala PAUD yang profesional yaitu sebagai berikut: (a) kepala PAUD adalah seorang dengan minimal memiliki kualifikasi akademik S1 PGPAUD atau S1 Psikologi Perkembangan.

Sebagaimana tuntutan dalam peraturan Menteri Pendidikan Nasional Republik Indonesia Nomor 13 Tahun 2007 tentang Standar Kepala Sekolah/Madrasah beserta lampirannya, (b) kepala PAUD adalah mereka yang berstatus pendidik dan memiliki pengalaman sebagai pendidik PAUD minimal selama 3 tahun.

Status dan pengalamannya sebagai pendidik PAUD tersebut sudah barang tentu akan sangat mempengaruhi wawasan terkait dengan penyelenggaraan PAUD baik secara teoritis maupun praktis, (c) kepala PAUD memiliki kompetensi kepribadian berupa kepribadian yang 
stabil dan mantap, (d) kepala PAUD memiliki jiwa kewirausahaan. Ini berarti seorang kepala PAUD adalah pemimpin PAUD yang berjiwa kewirausahaan, (e) kepala PAUD harus memiliki kemampuan dalam melakukan sepurvisi.

Ini berarti, kepala PAUD sebagai seorang pemimpin memiliki peran sebagai seorang supervisor. Supervisi itu sendiri adalah suatu proses pembimbingan dari pihak atasan (dalam konsep ini kepala PAUD) kepada pendidik PAUD maupun staf PAUD terkait dengan kinerjanya dalam menangani penyelenggaraan layanan PAUD untuk memperbaiki layanan PAUD agar ada peningkatan mutu PAUD, (f) kepala PAUD harus memiliki kompotensi manajereal.

Berpedoman pada uraian tokoh-tokoh diatas, maka profesonalisme kepala PAUD adalah seseorang yang dapat menggerakkan sumber daya manusia dalam suatu kelompok yang memiliki kriteria, di antaranya selalu meningkatkan kompetensi, menunjukkan kepribadian yang stabil, dapat memanfaatan kemajuan teknologi informasi, serta mampu melaksanakan manajemen lembaga dan tindak lanjutnya, melakukan tugas-tugas pengawasan dan pengendalian, serta mencerminkan jiwa kewirausahaan.

Banyak kepala PAUD yang tidak memenuhi standar Permendikbud Nomor 137 tahun 2014 tentang Standar Nasional Pendidikan Anak Usia Dini. Hal itu berdampak kepada kinerjanya. Masalah lain yaitu kepala PAUD yang orientasinya terlebih ke bisnis, kepala PAUD dengan wawasan yang masih sempit terkait ke PAUD-an, kurangnya komunikasi dengan rekan kerja berdampak pada dorongan dan keinginan bekerja, serta minimnya disiplin ketika melaksanakan profesi pekerjaan.

Gambaran di atas menunjukkan profesionalisme kepala PAUD belum tampak karena faktor latar belakang pendidikan. Latar belakang pendidikan merupakan salah satu tolok ukur kepala PAUD bisa dinyatakan profesional atau tidak. Diindikasikan tingginya tingkat latar belakang pendidikan akan menjadikan tinggi pula tingkat profesionalismenya dikarenakan luasnya ilmu dan wawasan yang diterima seorang individu dari lembaga pendidikan.

Latar belakang pendidikan merupakan proses atau tahapan pada pendidikan berkelanjutan yang dijelaskan dengan tingkat perkembangan peserta didik serta luas dan dalamnya pemahaman terhadap bahan pengajaran. Pendidikan formal merupakan pendidikan yang mempunyai bentuk tertentu yang terdapat di sekolah dan universitas. Pendidikan yang dilalui kepala sekolah terutama mempengaruhi penentuan kualitas lembaganya. Dari ilmu pendidikan yang dikuasai oleh kepala sekolah menjadikan kepala sekolah tangguh menghadapi permasalahan bahkan pertikaian yang muncul terkait dengan keprofesionalannya.

Kepala sekolah dengan pendidikan yang baik bisa dibentuk untuk mengembangkan sekolahnya dimasa depan karena pendidikan yang menjadikan seorang individu dapat dan untuk berkembang. Latar belakang pendidikan yang dimaksud dalam penelitian ini adalah tingkat pendidikan formal yang pernah diperoleh kepala sekolah berdasarkan ijazah terakhir. Proses membangun profesionalisme kepala PAUD harus berlangsung secara berkesinambungan dengan melibatkan fisik dan mental. Dimana dari segi mental salah satunya berkaitan dengan komunikasi interpersonal. Respon balik yang diberikan secara langsung oleh komunikan sehingga tercipta suasana dialogis, sikap transparansi, dan adanya kehangatan serta adanya dukungan. Hal ini sudah menjadi barang tentu yang harus dimiliki oleh 
Kepala PAUD dalam menjalankan tugasnya di lembaga. Secara umum komunikasi dinilai efektif bila rangsangan yang disampaikan kepala PAUD dapat ditangkap dan dipahami oleh penerima yakni guru, staf, wali peserta didik serta masyarakat. Dimana hal tersebut akan membantu profesionalisme kepala PAUD terwujud.

Komunikasi merupakan hal utama yang dibutuhkan dalam proses kehidupan sehari-hari. Menurut tubs dan Moss dalam (Ida Windi Wahyuni \& jamaludin Ancok, 2003) komunikasi akan efektif apabila memiliki unsur pemahaman, kesenangan, pengaruh pada sikap, hubungan yang makin baik, dan tindakan. Agar dapat berkomunikasi dengan jelas perlu menggunakan bahasa yang dapat dimengerti. Salah satu dari macam komunikasi yaitu komunikasi interpersonal. (Nurani Soyomukti, 2010)) komunikasi interpersonal adalah interaksi antara seorang individu dan individu lainnya tempat lambang-lambang pesan secara efektif digunakan, terutama dalam hal komunikasi antar manusia menggunakan bahasa. Artinya komunikasi interpersonal bisa terlaksana ketika adanya interaksi dari seseirang kepada orang lain dengan menggunakan bahasa.

Komunikasi interpersonal merupakan jenis komunikasi yang frekuensi terjadinya cukup tinggi dalam kehidupan sehari-hari. (Suranto AW, 2011) berpendapat ada beberap ciri-ciri komunikasi interpersonal, yakni: arus pesan dua arah yaitu sumber pesan dan penerima pesan dalam posisi yang sejajar, berlangsung biasanya pada suasana nonformal, umpan balik segera yaitu mempertemukan para pelaku komunikasi secara bertatap muka sehingga dapat diketahui umpan balik dengan segera, peserta komunikasi berada pada jarak dekat yaitu metode komunikasi antarindividu yang menuntut agar peserta komunikasi berada dalam jarak yang dekat, dan peserta komunikasi mengirim dan menerima pesan secara simultan dan spontan baik secara verbal amupun nonverbal.

Selanjutnya (Devito, 2011)), mengatakan bahwa komunikasi interpersonal yang efektif meliputi aspek sebagai berikut: (a) keterbukaan (openness) yaitu keinginan merespon sesuatu secara senang hati informasi yang diterima di pada proses hubungan interpersonal. Keterbukaan atau sikap terbuka sangat berpengaruh dalam menumbuhkan komunikasi interpersonal yang efektif, (b) empati (empathy) adalah turut rasa apa yang dirasakan seseorang atau tahap ketika seseorang merasakan perasaan seseorang dan menangkap arti perasaan itu kemudian mengkomunikasikannya dengan kepekaan sedemikian rupa hingga menunjukkan bahwa ia sungguhsungguh mengerti perasaan orang lain itu, (c) dukungan (supportiveness) adalah situasi yang terbuka untuk mendukung supaya komunikasi berjalan efektif. Sikap suportif merupakan sikap yang meminimalkan sikap defensif dalam komunikasi, (d) rasa positif (positiveness) adalah perasaan positif akan diri pribadi, kekuatan mendorong seseorang menjadi aktif dalam partisipasi dan keahlian menciptakan situasi komunikasi kondusif untuk berinteraksi secara efektif, (e) kesetaraan (equality) yaitu pengakuan kedua belah pihak untuk terus menghargai, bermanfaat dan mempunyai sesuatu yang bernilai untuk dihibahkan. Dalam melakukan komunikasi seseorang mempunyai arah dan tujuan sebagai pendorong untuk berkomunikasi.

Dengan begitu, kepala PAUD sebagai seorang pemimpin yang profesional, selain berperan melayani dan menolong pendidik 
dalam menyelenggarakan kegiatan belajar mengajar, juga mesti tercipta komunikasi yang baik antara kepala PAUD dengan para pendidik dan tenaga kependidikan karena komunikasi sebagai salah satu kegiatan yang sangat besar pengaruhnya pada keberhasilan suatu lembaga PAUD dalam mencapai tujuan. Misalnya, di suatu lembaga dibutuhkan kegiatan komunikasi interpesonal agar dapat terwujud kerjasama diantara mereka dalam mencapai tujuan pendidikan. Kemudian kepala PAUD juga berfungsi sebagai pemangku kebijakan maupun pengambil keputusan tertinggi di lembaga sekaligus bertindak tegas pada pendidik dan tenaga kependidikan yang tidak atau kurang disiplin dalam pelaksanaan tugas di lembaga PAUD. oleh karena hal itu, kepala PAUD harus sebenar-benarnya mengawasi, mengarahkan, membimbing, dan memberikan dorongan kepada pendidik dan tenaga kependidikan. Hal ini tidak akan lepas dari kegiatan komunikasi ienterpesonal.

Beberapa penelitian yang telah dilakukan sebelumnya, yakini penelitian oleh (Siti Hardiyanti, 2018) dengan judul "Hubungan komunikasi interpersonal kepala sekolah dengan kinerja guru di SMKN 2 tangerang selatan" memperoleh hasil terdapat korelasi yang rendah antara komunikasi interpersonal kepala sekolah dengan kinerja guru. Setidaknya jika komunikasi interpersonal kepala sekolah berjalan dengan baik, maka dapat memberikan kontribusi yang tinggi bagi kinerja guru. Selanjutnya penelitian (Siti Hardiyanti, 2018) dengan judul "Pengaruh Latar Belakang Pendidikan dan Pengalaman Mengajar terhadap Profesionalisme Guru Produktif Kompetensi Keahlian

Administrasi Perkantoran di Smk Kulon Progo.
Penelitian yang telah dilakukan oleh beberapa peneliti tersebut melihat pengaruh antara komunikasi interpersonal dengan kinerja guru, kemudian latar belakangg pendidikan terhadap profesionalisme guru produktif kompetensi keahlian administrasi perkantoran. Kebaruan dari penelitian ini yakni meneliti profesionalisme kepala PAUD yang sama-sama dipengaruhi oleh komunikasi interpersonal dan latar belakang pendidikan.

\section{METODE}

Metode penelitian ini korelasi dengan analisis regresi ganda. Penelitian ini dilakukan kepada kepala PAUD di Kabupaten Indragiri Hulu. Waktu penelitian pada bulan februari hingga maret 2020. Sampel dalam penelitian ini sebanyak 77 orang kepala PAUD. Pengambilan sampel menggunakan cluster sampling. Sesuai survei awal seluruh kepala PAUD yang berada di Kabupaten Indragiri Hulu berjumlah 326 yang terbagi di beberapa kecamatan. Sedangkan subyek penelitian dipilih dan ditetapkan menggunakan rumus Taro Yamane, yaitu:

$\mathbf{n}=\frac{\mathrm{N}}{\mathrm{N} \cdot \mathrm{d}^{2}+1}$

\section{Dimana:}

$$
\begin{array}{ll}
\mathrm{n} & =\text { jumlah sampel } \\
\mathrm{N} & =\text { jumlah populasi } \\
\mathrm{d}^{2} & =\text { presisi yang ditetapkan }
\end{array}
$$

Maka didapatkan hasil berjumlah 77 responden. Data penelitian diperoleh dengan menggunakan angket. Analisis data dari masing-masing variabel yakni profesionalisme kepala PAUD, komunikasi interpersonal dan latar belakang pendidikan dimulai dari pengujian validitas, reliabilitas, uji persyaratan dan 
uji hipotesis untuk menjawab rumusan permasalahan penelitian.
Bentuk hubungan antar variabel seperti pada gambar di bawah ini:

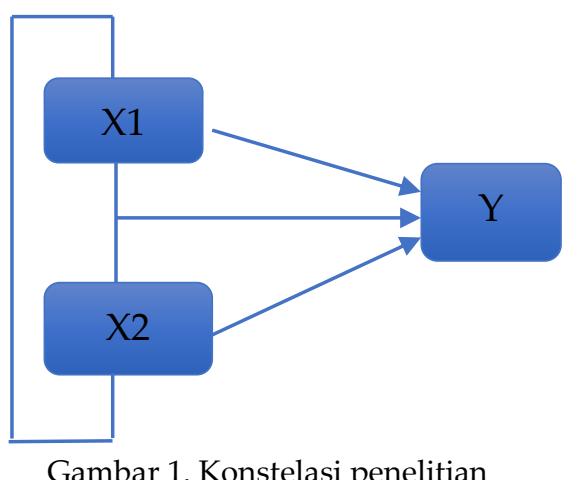

\section{HASIL TEMUAN}

Berdasarkan perhitungan nilai kontribusi korelasi ganda koefisien korelasi didapatkan hasil $0,25 \%$. Hal ini menunjukkan bahwa pengaruh komunikasi interpersonal dan latar belakang pendidikan terhadap profesionalisme kepala PAUD SeKabupaten Indragiri Hulu sangat kecil, sedangkan sisanya 99,75\% dipengaruhi faktor lain.

Selanjutnya dilakukan perhitungan uji signifikansi, dimana diperoleh hasil nilai $F_{\text {hitung }}=0,09$. Seterusnya melihat tabel distribusi $\mathrm{F}$ pada derajat bebas $\mathrm{N} 1=$ 2 dan N2 = 74 pada taraf signifikansi 0,05 diperoleh $\mathrm{F}_{\text {tabel }}=3,13$. Jadi $\mathrm{F}_{\text {hitung }}<\mathrm{F}_{\text {tabel }}=$ $0,09<3,13$.

Kriteria pengujian:

Jika $F_{\text {hitung }}<\mathrm{F}_{\text {tabel, }}$ maka $\mathrm{H}_{0}$ ditolak Jika Fhitung $<\mathrm{F}_{\text {tabel, }}$ maka $\mathrm{H}_{0}$ diterima

Berdasarkan signifikansi:

Jika $F_{\text {hitung }}<\mathrm{F}_{\text {tabel, }}$ maka signifikan Jika $F_{\text {hitung }}<\mathrm{F}_{\text {tabel, }}$ maka tidak signifikan

Berdasarkan perhitungan di atas, maka terima $\mathrm{H}_{0}$ artinya tidak terdapat pengaruh yang signifikan antara komunikasi interpersonal dan latar belakang pendidikan terhadap profesionalisme kepala PAUD SeKabupaten Indragiri Hulu.

\section{PEMBAHASAN}

Sumber daya manusia merupakan barang tentu faktor keberhasilan seluruh jenjang dan lembaga pendidikan, tidak terkecuali pendidikan anak usia dini. Salah satunya adalah kepala PAUD. Kepala PAUD harus mampu mengarahkan dan membuat bergerak pendidik, tenaga kependidiikan, peserta didik, wali peserta didik, serta stakeholder untuk sampai pada tujuan yang telah direncanakan. Dalam hal ini, kepala PAUD harus menjadi seorang yang profesional. Profesionalisme kepala PAUD akan terwujud ketika kepala PAUD dapat menggerakkan seluruh komponen dalam lembaga PAUD sesuai dengan standar dan kriteria dari Permendikbud.

Peraturan Menteri Pendidikan Nasional Republik Indonesia Nomor 13 Tahun 2007 tentang Standar Kepala Sekolah memiliki kualifikasi akademik S1 PG PAUD atau Psikologi Perkembangan Saat ini kepala PAUD beberapa lembaga dari variabel latar belakang pendidikan untuk kepala PAUD itu sendiri sangat berpengaruh dalam memaksimalkan perkembangan kemajuan lembaga PAUD. 
dalam penelitian ini ditemukan 42 orang berlatar belakang pendidikan formal SMA dan Sarjana non-PAUD. Karena keterbelakangan pendidikan ini kepala PAUD biasanya belum tentu bisa berperan aktif dalam kerjanya dikarenakan masalah pendidikan tersebut. Kepala PAUD yang keterbelakangan pendidikan formalnya pendidikan terkahir SMA tersebut tidak memastikan untuk bekerja selaras dengan yang pendidikan terakhir gelar sarjana.

Selanjutnya pendidikan terakhir gelar sarjana juga tidak memastikan dapat bekerja selaras dengan pendidikan terakhir gelar sarjana PAUD. Namun tidak ada kemungkinan besar bagi pendidikan terakhir SMA dan tidak sarjana PAUD bisa melebihi gelar sarjana PAUD dikarenakan mempunyai skill atau keahlian, kemampuan dan pengalaman selama bekerja. Hal ini didukung oleh pendapat (Wiyani, 2015) bahwa menjadi kepala PAUD yang profesional harus memiliki pengalaman pendidik PAUD minimal selama 3 tahun karena status dan pengalaman tersebut akan sangat berpengaruh pada wawasan tentang penyelenggaraan PAUD baik secara teoritis dan praktis. Selanjutnya (Wiyani, 2017) mengatakan dari segi mental, profesionalisme kepala PAUD juga dipengaruhi oleh rasa percaya diri, demokratis, tanggung jawab, dan originalitas. Akan tetapi perilaku kepala PAUD harus memperhatikan komunikasi dengan rekan kerjanya. Karena komunikasi sangat berpengaruh dalam kelangsungan kerja.

Sejalan dengan (Suranto AW, 2011) menyatakan bahwa teori komunikasi insani atau yang dinamakan dengan human communication yang antarpribadi maupun nonantarpribadi segalanya mengenai pengendalian lingkungan agar mendapatkan balasan dari bentuk fisik, sosial dan ekonomi. Keberhasilan yang relatif dalam melakukan pengendalian lingkungan melalui komunikasi menambah kemungkinan menjadi bahagia. Selain itu komunikasi interpersonal juga akan berpengaruh kuat terhadap profesionalisme kepala PAUD untuk melakukan pengendalian agar dalam bekerja di lembaga akan memperoleh tujuan yang diinginkan sendiri atau standar pemerintahan.

Komunikasi interpersonal yang lebih lengkap, yaitu: selektif terhadap siapa yang akan diajak berkomunikasi, sistemik atau dipengaruhi oleh budaya, pengalaman pribadi dan sebagainya, unik yang mampu mengembangkan ritme dan pola tersendiri yang khas dan berkesinambungan serta berkomunikasi secara kontinyu dan bersamaan. Perilaku kepala PAUD harus memperhatikan komunikasi dengan rekan kerjanya. Karena komunikasi sangat berpengaruh dalam kelangsungan kerja.

\section{SIMPULAN}

Penelitian ini menunjukkan bahwa tidak terdapat pengaruh yang siginifikan antara komunikasi interpersonal dan latar belakang pendidikan terhadap profesionalisme kepala PAUD di Kabupaten Indragiri Hulu.

\section{DAFTAR PUSTAKA}

Devito, J. (2011). Komunikasi Antar Manusia. Karisma Publishing.

Ida Windi Wahyuni, \& jamaludin Ancok. (2003). Hubungan Antara Persepso Gaya Kepemimpinan Situasional dan Efektivitas Komunikasi Interpersonal dengan Komitmen Kerja. 17.2, 235. http://ilib.ugm.ac.id/jurnal/download.php?d ataId $=7042$

Kusnandar. (2007). Guru Profesional. PT Raja Grafindo. 
Nurani Soyomukti. (2010). Pengantar Ilmu Komunikasi. Ar-Ruzz Media.

Peraturan Menteri Pendidikan Nasional Republik Indonesia Nomor 13 Tahun 2007. (n.d.). Standar Nasional Pendidikan Peraturan Menteri Pendidikan Nasional Republik Indonesia Nomor 13 Tahun 2007 tentang Standar Kepala Sekolah/Madrasah (Vol. 46, Issue

https://doi.org/10.2320/materia.46.171

Hardiyanti, S. (2018). Hubungan Komunikasi Interpersonal Kepala Sekolah Dengan
Kinerja Guru Di Smkn 2 Tangerang Selatan.

Danim, S. (2002). Upaya Peningkatan Profesionalisme Tenaga Kependidikan. Pustaka setia.

Suranto AW. (2011). Komunikasi Interpersonal. Graha Ilmu.

Wiyani, N. A. (2015). Manajemen PAUD Bermutu: Konsep dan Praktik MMT di KB,TK/RA. Gava Media.

Wiyani, N. A. (2017). Profesionalisasi Kepala PAUD. Ar-Ruzz Media. 